\title{
The Effects of Culture Conditions on the Secretion of Human Lysozyme by Saccharomyces cerevisiae A2-1-1A
}

\author{
Kimihisa IchIKawa, Koji Komiya, ${ }^{*, \dagger}$ Katsunori SuzuKI, ${ }^{*}$ \\ Tadaatsu NAKAHARA and Yoshifumi JIGAMI $*,+\dagger$ \\ Institute of Applied Biochemistry, University of Tsukuba, \\ Tennoudai 1-1-1, Tsukuba, Ibaraki 305, Japan \\ * Gene Technology Section, Biological Chemistry Division \\ National Chemical Laboratory for Industry, Higashi 1-1, \\ Tsukuba, Ibaraki 305, Japan \\ Received April 12, 1989
}

\begin{abstract}
The effects of initial glucose concentrations on the cell growth, glucose usage, and human lysozyme (HLY) secretion under the ENO1 promoter were examined in the Saccharomyces cerevisiae strain A2-1-1A harboring a multicopy plasmid. By increasing the initial glucose from $2 \%$ to $10 \%$, the HLY secretion increased $7 \sim 8$ fold although the cell growth was not affected. By adding a mixture of mineral salts to the basal medium, the HLY secretion was increased about twice due to the continuity of the HLY expression at the stationary phase of cell growth.

The high HLY secretion (5.5 mg per liter, 47-fold higher than the original level) was achieved by the strain A2-1-1A grown in the synthetic basal medium containing $10 \%$ initial glucose, and supplemented with mineral salts containing ammonium sulfate, potassium phosphate, potassium chloride, magnesium sulfate, and iron sulfate.
\end{abstract}

Human lysozyme (HLY, EC 3.2.1.17) is a bacteriolytic enzyme catalyzing the hydrolysis of the $\beta-(1 \rightarrow 4)$ glycosidic bonds of the polysaccharide of bacterial cell walls or chitin ${ }^{1)}$ and has a potential as a safer non-allergic antiinflammation drug. ${ }^{2)}$ We were already successful in producing the secretion of HLY by expressing a hybrid pre- $H L Y$ gene containing the chicken lysozyme signal sequence and the HLY structural gene, ${ }^{3)}$ both of which were chemically synthesized, under the control of the $G A L 10$ promoter in $S$. cerevisiae strain $\mathrm{KK} 4{ }^{4}{ }^{4}$ In our previous paper, we reported the HLY secretion within a short period (about $24 \mathrm{hr}$ ) by replacing the original GAL10 promoter with ENOI promoter ${ }^{5}$ in yeast cells grown on glucose, a more convenient carbon source than galactose. ${ }^{6)}$ However, the amount of secreted HLY under the ENOI promoter was half of that under the GAL1O promoter in the strain $\mathrm{KK} 4$, and was still small (about $0.2 \sim 0.6 \mathrm{mg} / \mathrm{l}$ of culture medium).

To obtain a high level of expression of foreign genes and secretion of their gene products, several approaches are possible by genetic engineering techniques and by the modification of host cells to isolate supersecreting mutants. ${ }^{7,8)}$ The improvements are effective, for example, on the stability of plasmids ${ }^{9)}$ and mRNA transcription, ${ }^{10.11)}$ on the initiation of the translation, ${ }^{12)}$ and on the efficiency of processing (translocation of preprotein containing a signal peptide in the ER membrane) ${ }^{13)}$ and secretion (transport of protein from ER to cell surface). However, there are few reports on the analysis of the culture conditions for the production and secretion of foreign proteins by a recombinant yeast.

In this paper, we describe our attempts to increase the secretion of HLY by increasing

\footnotetext{
+ Present address: Central Technical Research Laboratory, Nippon Oil Company, Ltd., Chidori-cho 8, Naka-ku, Yokohama 231, Japan.

To whom correspondence should be addressed
} 
the initial glucose concentration and other culture medium components including the amounts of inorganic salts for $S$. cerevisiae strain A2-1-1A in which the level of HLY secretion was higher than in the strain $\mathrm{KK} 4$ with $2 \%$ initial glucose, ${ }^{6)}$ and our findings that the HLY production and secretion continues without cell growth with an increased supply of glucose and mineral salts in the synthetic basal medium.

\section{Materials and Methods}

Strains and plasmids. The E. coli strain C600 $\left(F^{-}\right.$, thil, thrl, leuB6, lacYI, ton $A 21$, supE44 $)^{14)}$ was used for bacterial transformation. The $S$. cerevisiae strain A2-1-1A (MATa, SUC2, CUP1, mal, leu 2$)^{15)}$ which was constructed by back-crossing a leu2 mutant derived from X2180-1A (MATa, SUC2, CUPl, mal) with its mating type counterpart, X2180-1B, was also used for the secretion of HLY. The yeast $S$. cerevisiae strain $\mathrm{KK} 4$ (MAT 2 , ura3, his 1 or his3, trp1, leu2, gal80 ${ }^{16)}$ is a recessive mutant in GAL80 leading to constitutive expression of $G A L$ cluster genes. The strains A2-1-1A and KK4 were used as host strains for plasmid transformation.

The multi-copy plasmids pESH and pESH-2 containing a single or double HLY transciptional unit(s), ${ }^{6}$, which corresponds to the yeast ENOI promoter-chemically synthesized chicken lysozyme signal sequence and HLY gene $-2 \mu \mathrm{m} F L P$ terminator, were used to secrete mature human lysozyme.

Media. The E. coli cells were grown in LB-broth ( $1 \%$ Bacto trypton, $0.5 \%$ yeast extract, $0.5 \% \mathrm{NaCl}, 0.2 \%$ glucose). Ampicillin was added where appropriate to a final concentration of $80 \mu \mathrm{g} / \mu \mathrm{l}$. The $S$. cerevisiae cells were grown in YPD medium $(2 \%$ Bacto pepton, $1 \%$ yeast extract, $2 \%$ glucose). Transformation of $E$. coli and $S$. cerevisiae was done by the methods of Cohen et al. ${ }^{17)}$ and Ito t $a l .{ }^{18}$ respectively. In the experiments to express the $H L Y$ gene, a synthetic medium was used containing $0.67 \%$ Bacto yeast nitrogen base without amino acid, supplemented with an amino acid mixture $(20 \sim 375 \mu \mathrm{g} / \mathrm{ml})$ lacking leucine. ${ }^{19)}$ Glucose sterilized by autoclaving was added separately to the minimal medium as a carbon source, as described in the text and figure legends.

Enzymes and chemicals. The restriction enzymes were purchased from Toyobo (Osaka, Japan) and Takara Shuzo (Kyoto, Japan); T4-DNA ligase, T4-polynucleotide kinase, and the Klenow fragment of $E$. coli DNA polymerase (Pol Ik) were from Toyobo (Osaka, Japan). Zymolyase 100T was obtained from Seikagaku Kogyo (Tokyo, Japan). $\left[\alpha-{ }^{32} \mathrm{p}\right] \mathrm{dCTP}(600 \mathrm{Ci} / \mathrm{mmol})$ and ${ }^{125} \mathrm{I}-$ protein A was from Amersham Japan (Tokyo, Japan). HLY and Micrococcus lysodeikticus were from Sigma (St. Louis, U.S.A.). Anti-HLY IgG (rabbit serum) was from Alpha Therapeutic Corp (Los Angeles, U.S.A.). Anticarboxypeptidase $\mathrm{Y}$ (CPY) rabbit serum was made by immunization of a rabbit with CPY which was obtained from Takara Shuzo (Kyoto, Japan). The other chemicals used were of analytical or biochemical reagent grade. Standard techniques of restriction endonuclease digestion, ligation, and gel electrophoresis were done as described by Maniatis et al. ${ }^{20)}$ The amount of residual glucose in the medium was measured by using an enzymatic assay kit supplied as a Glucose C-Test Wako (Wako Pure Chemical Industries, Osaka, Japan).

Measurement of HLY secretion. Yeast cells carrying the plasmid containing the HLY transcriptional unit(s) were cultivated in an Erlenmeyer flask for 5 days at $30^{\circ} \mathrm{C}$ on a reciprocal shaker $(220 \mathrm{rpm})$, and the course of the secretion of HLY was monitored by measuring the HLY activity. The HLY activity was measured photometrically by a modification of the method of Mörsky. ${ }^{21}$ The assay sample $(200 \mu \mathrm{l})$ was added to $800 \mu \mathrm{l}$ of a cell suspension of $M$. lysodeikticus $(0.15 \mathrm{mg} / \mathrm{ml})$ in $50 \mathrm{~mm} \mathrm{Na}$-phosphate buffer ( $\mathrm{pH}$ 6.4). The initial decrease in the absorbance at $450 \mathrm{~nm}$ of the mixture caused by the lysis of bacterial cells was measured at room temperature for $3 \mathrm{~min}$. One unit (decrease of 0.001 in absorbance at $450 \mathrm{~nm}$ per min) corresponds to $0.02 \mu \mathrm{g}-\mathrm{HLY} / \mathrm{ml}$-culture medium under our assay conditions.

Western and Northern blot analysis. The intracellular HLY synthesized in $S$. cerevisiae cells was analyzed by Western blotting and quantified by a densitometric method. The total cellular RNA was prepared from yeast cells and HLYmRNA in the total yeast RNA was analyzed by Northern blot analysis and quantified by densitometry as reported previously. ${ }^{16)}$

\section{Results}

\section{Effects of initial glucose concentration}

When the A2-1-1A transformants were cultivated in the original synthetic medium containing $2 \%$ glucose, no residual glucose was detected at the early stationary phase (about $24 \mathrm{hr}$ ) (Fig. 1). As a supply of glucose will be essential not only for the cell growth but also for the expression of the ENOI promoter directing the $H L Y$ gene and for the resulting HLY secretion, it is of interest to examine whether the larger HLY secretion is achieved or not by an increase in the initial glucose. We examined the effects of initial glucose con- 


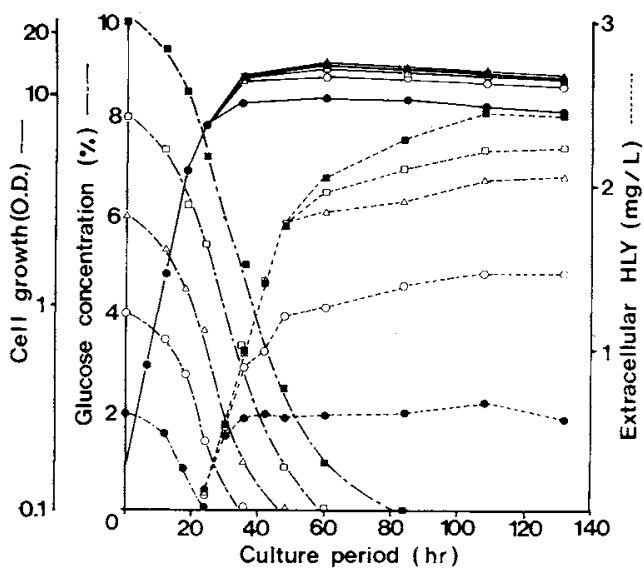

Fig. 1. Courses of Cell Growth, Glucose Concentration, and the Amounts of Extracellular HLY.

Seed cultures of the strain A2-1-1A carrying the pESH-2 plasmid were prepared by inoculating loopfuls of cells grown in and L-shaped test tube $(5 \mathrm{ml})$ into $300-\mathrm{ml}$ Erlenmeyer flasks containing $50 \mathrm{ml}$ of the synthetic culture medium containing $4 \%$ glucose, followed by incubation at $30^{\circ} \mathrm{C}$ for 3 days. The seed cultures $(3 \mathrm{ml})$ were transferred to $500-\mathrm{ml}$ Sakaguchi flasks containing $150 \mathrm{ml}$ of a synthetic medium containing $2 \%$ glucose (O), $4 \%$ glucose $(O), 6 \%$ glucose $(\triangle), 8 \%$ glucose $(\square)$, and $10 \%$ glucose $(\boldsymbol{\square})$, respectively. The flasks were reciprocally shaken at $30^{\circ} \mathrm{C}$. The data represent the average values obtained from at least two independent experiments. Cell growth, extracellular HLY activity, and glucose use are indicated by the straight lines ( - ), dotted lines ----), and semidotted lines (-- - ), respectively.

centration on the cell growth and the HLY secretion. As shown in Fig. 1, it is noteworthy that not only $6 \%$ but also $10 \%$ of the initial glucose is completely exhausted by the strain A2-1-1A (at $48 \mathrm{hr}$ of cultivation in $6 \%$ glucose medium and at $84 \mathrm{hr}$ of cultivation in $10 \%$ glucose medium), while $6 \%$ glucose was not completely used by strain KK4 even after $120 \mathrm{hr}$ of cultivation (data not shown). The increase in the initial glucose concentration from $2 \%$ to $10 \%$ did not significantly affect the cell growth of the strain A2-1-1A, but did affect the HLY secretion level. The extracellular HLY activity was increased from about $0.55 \mathrm{mg} / \mathrm{l}$ to about $2.4 \mathrm{mg} / \mathrm{l}$ by increasing the initial glucose concentration from $2 \%$ to $10 \%$. With $2 \%$ or $4 \%$ initial glucose, the increase of the HLY secretion began to decline after $30 \mathrm{hr}$ or $36 \mathrm{hr}$ at which time glucose in the medium
A.

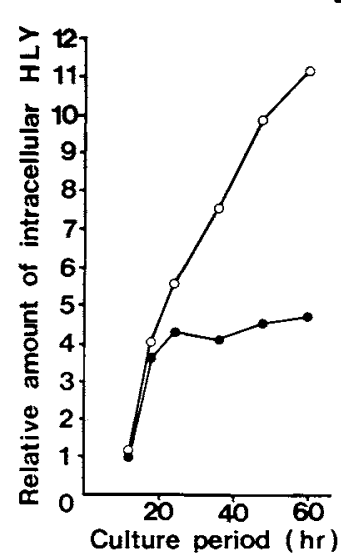

B.

\section{2\% Glucose} $12 \mathrm{~h}$ 18h 24h 36h 48h 60h

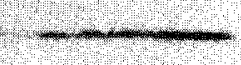

$12 \mathrm{~h}$ 18h 24h 36h $48 \mathrm{~h}$ 6Oh

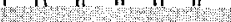

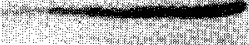

C.

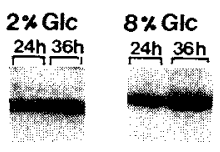

$8 \%$ Glucose

Fig. 2. Courses of the Amount of Intracellular HLY and of the Intracellular CPY.

The strain A2-1-1A harboring the pESH-2 plasmid was grown in a synthetic medium containing $2 \%$ glucose (-) or $8 \%$ glucose $(\mathrm{O})$. The cell extracts containing loading buffer $(20 \mu \mathrm{l})$ prepared by the method of Botstein et al. ${ }^{22)}$ were put onto a $15 \%$ polyacrylamide slabe gel and electrophoresed by the method of Laemmli. ${ }^{23)}$ After proteins were electrophoretically transferred to nitrocellulose filters, antibody binding was done in a blocking buffer $(1 \%$ gelatin, $20 \mathrm{~mm}$ Tris, $500 \mathrm{~mm} \mathrm{NaCl}, 0.05 \%$ Tween-20, pH 7.5) with $100 \mu \mathrm{l}$ of HLY antiserum (B) or $40 \mu 1$ of CPY antiserum (C). Filters were washed with blocking buffer and filter-bound antibodies were labeled by incubation in blocking buffer containing $5 \mu \mathrm{Ci}$ of ${ }^{125}$ I-labeled protein A. Filters were washed and the were exposed to $\mathrm{X}$-ray film with intensifying screens at $-80^{\circ} \mathrm{C}$

A, A densitometry was used to quantify the band intensities on an exposed film. The values showed the relative amount of the HLY band compared with the value obtain from $2 \%$ glucose at $24 \mathrm{hr}$ of culture. B, Autoradiogram of western blot gels to measure intracellular HLY under $2 \%$ or $8 \%$ initial glucose concentrations during culture (from $12 \mathrm{hr}$ to $60 \mathrm{hr}$ ). C, Autoradiogram of western blot gels to measure intracellular CPY with $2 \%$ or $8 \%$ initial glucose concentrations at $24 \mathrm{hr}$ and $36 \mathrm{hr}$ of cultivation.

was exhaused by the cells. But with $6 \%, 8 \%$, or $10 \%$ initial glucose, the HLY secretion still continued to increase linearly from $24 \mathrm{hr}$ to $48 \mathrm{hr}$ without the cell growth. The results suggested that HLY secretion might be continued by the strain A2-1-1A supplied with glucose in the medium.

As shown in Fig. 2, the amount of intracellular HLY with $8 \%$ initial glucose in- 
creased linearly after the cells entered the stationary phase at about $24 \mathrm{hr}$ until $60 \mathrm{hr}$ at which time glucose was just exhausted from the medium, while the increase of the intracellular HLY with $2 \%$ initial glucose was almost stopped after $24 \mathrm{hr}$ (Fig. 2A and B). The increase of the intracellular HLY level was assumed to be associated with the increase of the HLY expression under the ENOI promoter, because the amount of a yeast vacuolar protein, intracellular carboxypeptidase $\mathrm{Y}$ whose production was not reported to be regulated by a glycolytic carbon source like glucose, was not changed greatly by increasing the initial glucose concentration in the medium (Fig. 2C). The above estimation was also supported by the fact that the level of HLY secretion was not changed by increasing the concentration of a non-fermentable carbon source (glycerol plus lactate) instead of glucose in the medium (data not shown).

In contrast, no increase of the extracellular HLY activity was observed in the strain KK4 after $94 \mathrm{hr}$ of cultivation by increasing the initial glucose cncentration from $4 \%$ to $6 \%$, although the amount of intracellular HLY in the cells grown on $6 \%$ glucose was larger than that in the cells grown on $4 \%$ glucose (data not shown). Therefore, it is found that the strain A2-1-1A has a higher ability to use the glucose in the medium and to produce HLY directed by the ENO1 promoter followed by the HLY secretion than the strain KK4. However, it is not clear how glucose affects the HLY secretion by yeast. The cell wall components may be changed at the stationary phase as a consequence of the presence or the absence of residual glucose in the medium. Alternatively, it is also possible that the HLY secretion may be caused by the cellular autolysis at the stationary phase. This possibility, however, is unlikely because no evidence suggesting the cellular autolysis, such as an increase of $\mathrm{pH}$, a flocculation of cells, or a leak of nucleic acid (judged from the absorbance at $260 \mathrm{~nm}$ in the medium) was observed in the cells cultivated for $120 \mathrm{hr}$ in $4 \%$ glucose (data not shown). Further, the above conclusion was supported by the result that the number of viable cells at stationary phase $(120 \mathrm{hr})$ was not changed between the cultivations under different glucose concentrations $(2 \%, 4 \%$, and $6 \%$ ), in spite of the large differences in the secretion of HLY (data not shown). However, a further analysis will be necessary to establish the relationship between the glucose concentration and the foreign protein secretion.

\section{Effects of other culture medium components on $H L Y$ secretion}

When the strain A2-1-1A was used for the HLY production, the HLY secretion was linearly increased by increasing the initial glucose from $2 \%$ to $4 \%$, but the rate of increase was decreased with $6 \%$ glucose and became constant with $8 \%$ or $10 \%$ glucose (Fig. 3). These results suggest that the other components of the culture medium except the carbon source may not be sufficient for the HLY production and secretion. The components of basal medium will be sufficient for the production of essential cellular components, but not for the additional production of non-essential foreign proteins. Thus, the effects of other culture medium components, such as nitrogen source, vitamins, and mineral

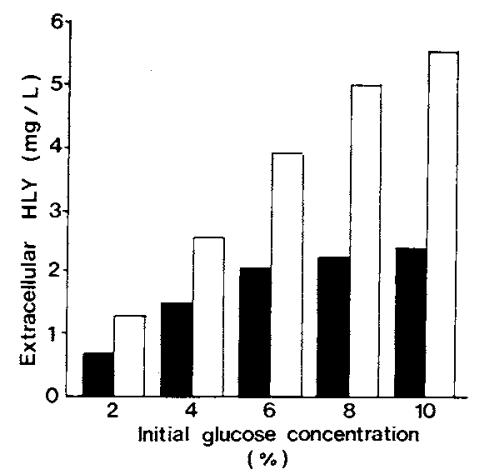

Fig. 3. Relationship between Initial Glucose Concentration and HLY Secretion.

The strain A2-1-1A carrying pESH-2 was grown for $120 \mathrm{hr}$ in SD basal medium either enriched with additional supplements containing $\left(\mathrm{NH}_{4}\right)_{2} \mathrm{SO}_{4}(5 \mathrm{~g} / 1) . \mathrm{K}_{2} \mathrm{H}$ $\mathrm{PO}_{4}(\mathrm{lg} / \mathrm{l}), \mathrm{KCl}(0.5 \mathrm{~g} / \mathrm{l}), \mathrm{FeSO}_{4} \cdot 7 \mathrm{H}_{2} \mathrm{O}(20 \mathrm{mg} / \mathrm{l})$, and $\mathrm{MgSO}_{4} \cdot 7 \mathrm{H}_{2} \mathrm{O}(0.5 \mathrm{~g} / 1)(\square)$ or with no enrichment ( ), under different concentrations of initial glucose ranging from $2 \%$ to $10 \%$. 
Table I. Effects of Mineral Salts and a Vitamin on HLY Secretion

\begin{tabular}{|c|c|c|c|c|c|c|c|}
\hline \multicolumn{5}{|c|}{ Enriched element ${ }^{a}$} & \multirow{2}{*}{$\begin{array}{c}\text { Cell } \\
\left(\text { O.D. }{ }_{660}\right)\end{array}$} & \multicolumn{2}{|c|}{ Extracellular HLY } \\
\hline $\mathrm{K}_{2} \mathrm{HPO}_{4}$ & $\begin{array}{c}\mathrm{MgSO}_{4}, \mathrm{KCl} \\
\mathrm{FeSO}_{4}\end{array}$ & $\left(\mathrm{NH}_{4}\right)_{2} \mathrm{SO}_{4}$ & $\mathrm{CaCl}_{2}$ & Biotin & & $(\mathrm{mg} / \mathrm{l})$ & $(\mu \mathrm{g} / 1 / \mathrm{O} . \mathrm{D})$. \\
\hline- & - & - & - & - & 11.0 & 1.0 & 90 \\
\hline+ & - & - & - & - & 11.1 & 1.5 & 135 \\
\hline+ & + & - & - & - & 10.9 & 1.9 & 174 \\
\hline+ & + & + & - & - & 10.4 & 2.2 & 212 \\
\hline+ & + & + & + & - & 10.6 & 1.7 & 160 \\
\hline+ & + & + & + & + & 17.0 & 1.8 & 106 \\
\hline
\end{tabular}

a The strain A2-1-1A carrying the pESH-2 plasmid was cultivated for $120 \mathrm{hr}$ in $150 \mathrm{ml}$ of SD basal medium supplemented with $(+)$ or without $(-)$ different combinations of $\left(\mathrm{NH}_{4}\right)_{2} \mathrm{SO}_{4}(5 \mathrm{~g} / \mathrm{l}), \mathrm{K}_{2} \mathrm{HPO}_{4}(1 \mathrm{~g} / \mathrm{l})$, $\mathrm{MgSO}_{4} \cdot 7 \mathrm{H}_{2} \mathrm{O}(0.5 \mathrm{~g} / 1), \mathrm{KCl}(0.5 \mathrm{~g} / 1), \mathrm{FeSO}_{4} \cdot 7 \mathrm{H}_{2} \mathrm{O}(20 \mathrm{mg} / 1), \mathrm{CaCl}_{2} \cdot 2 \mathrm{H}_{2} \mathrm{O}(0.5 \mathrm{~g} / \mathrm{l})$, and biotin $(20 \mu \mathrm{g} / \mathrm{l})$.

salts, on the HLY secretion were examined.

First of all, the concentrations of the mineral salts were increased as follows; $\left(\mathrm{NH}_{4}\right)_{2} \mathrm{SO}_{4}$, $5 \mathrm{~g} / 1 \rightarrow 10 \mathrm{~g} / \mathrm{l} ; \mathrm{K}_{2} \mathrm{HPO}_{4}, 0 \mathrm{~g} / 1 \rightarrow 1 \mathrm{~g} / 1 ; \mathrm{MgSO}_{4}$. $7 \mathrm{H}_{2} \mathrm{O}, 0.5 \mathrm{~g} / \mathrm{l} \rightarrow 1 \mathrm{~g} / \mathrm{l} ; \mathrm{KCl}, 0 \mathrm{~g} / \mathrm{l} \rightarrow 0.5 \mathrm{~g} / \mathrm{l} ; \mathrm{Fe}-$ $\mathrm{SO}_{4} \cdot 7 \mathrm{H}_{2} \mathrm{O}, 0.2 \mathrm{mg} / 1 \rightarrow 20.2 \mathrm{mg} / 1 ; \mathrm{CaCl}_{2} \cdot 2 \mathrm{H}_{2} \mathrm{O}$, $0.1 \mathrm{~g} / \mathrm{l} \rightarrow 0.6 \mathrm{~g} / \mathrm{l}$; and biotin, $2 \mu \mathrm{g} / 1 \rightarrow 22 \mu \mathrm{g} / 1$, and the effects of individual component on the HLY secretion were compared between media containing different combinations of mineral salt enrichment. As shown in Table I, among the mineral salts examined, the addition of $\left(\mathrm{NH}_{4}\right)_{2} \mathrm{SO}_{4}, \mathrm{~K}_{2} \mathrm{HPO}_{4}, \mathrm{MgSO}_{4} \cdot 7 \mathrm{H}_{2} \mathrm{O}$, $\mathrm{KCl}$, and $\mathrm{FeSO}_{4} \cdot 7 \mathrm{H}_{2} \mathrm{O}$ was found to improve the HLY secretion, while no differences were observed in the growth of the strain A2-1-1A. The effects of each mineral salt enrichment on the HLY secretion were summarized as follows; $\mathrm{K}_{2} \mathrm{HPO}_{4}, 1.5$-fold; $\mathrm{MgSO}_{4} \cdot 7 \mathrm{H}_{2} \mathrm{O}$ plus $\mathrm{KCl}$ plus $\mathrm{FeSO}_{4} \cdot 7 \mathrm{H}_{2} \mathrm{O}, 1.3$-fold; and $\left(\mathrm{NH}_{4}\right)_{2}-$ $\mathrm{SO}_{4}, 1.2$-fold, judged from the increase of extracellular HLY per cell density (mg/l/O.D.). The addition of biotin, known as an essential vitamin for several strains of $S$. cerevisiae, resulted in an increase of the final cell density, but in a great decrease of the extracellular HLY. In summary, it was possible to increase the HLY secretion level more than twice by adding a mixture of effective mineral salts to the SD basal medium (from $1.0 \mathrm{mg} / \mathrm{l}$ to $2.2 \mathrm{mg} / \mathrm{l}$ ) (Table I).

We further examined whether the effects of mineral salts and initial glucose concentrations

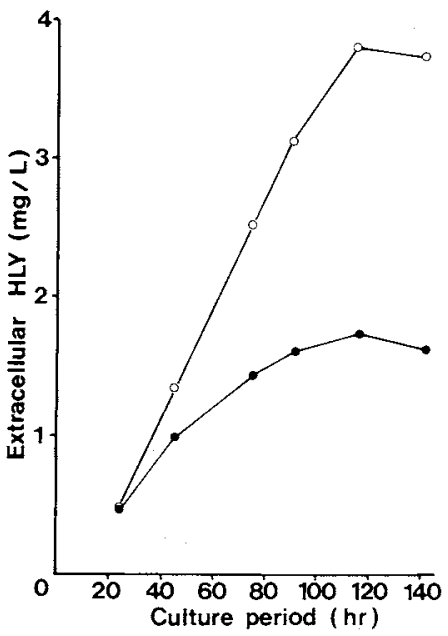

Fig. 4. Effects of Mineral Salts Enrichment on HLY Secretion.

The strain A2-1-1A carrying pESH-2 was grown in SD basal medium containing $6 \%$ glucose without mineral salts enrichment (O), and enriched with the supplement of mineral salts described in the legend to Fig. $3(0)$.

on the level of HLY secretion were additive or not. As shown in Fig. 3, the amount of extracellular HLY was higher in the medium enriched with the effective mineral salts than in the medium without enrichment with any glucose concentrations and was increased linearly by the stepwise increase of the glucose concentration from $2 \%$ to $10 \%$, suggesting that the effects of mineral salts and initial glucose concentrations were additive on the HLY secretion. The rate of glucose usage was not 
different between the cells grown in the SD basal medium containing $6 \%$ glucose either supplemented with or without the effective mineral salts (data not shown). Accordingly, it was suggested that the increase of the HLY secretion was not due to the change of the intracellular glucose concentration as described previously, but due to the other unknown factors, which was affected by the enrichment of mineral salts. In addition, as shown in Fig. 4, the increase in the HLY secretion continued during the stationary phase after $44 \mathrm{hr}$ cultivation by the enrichment of effective mineral salts, indicating that the maximal increase of HLY secretion by the effective mineral salts was due to not only the increase of HLY production but also the long continuity of HLY secretion. However, it is not clear why the production of HLY still continues up to the late stationary phase without cell growth after enrichment with effective mineral salts. One possibility is that the transcriptional and translational machineries may still remain active until the late stationary phase. In any case, since the possibility cannot be ruled out that the concentrations of effective mineral salts including non-effective calcium chloride are not optimum for HLY production and secretion, a further increase in the HLY secretion will be available by analysing more precisely the optimum concentrtions of the effective mineral components described above.

\section{HLY secretion under the optimum con- ditions}

The level of HLY secretion under the optimum conditions so far examined was analysed using the strain A2-1-1A harboring a pESH-2 plasmid which contained a duplicated HLY transcriptional unit ${ }^{6)}$ and compared with the original level of the HLY secretion by the strain KK4 harboring a pESH plasmid.

The results are summarized in Table II. The amounts of HLY secreted by the strain A2-1$1 \mathrm{~A}$ were $2 \sim 3$ fold larger (from $0.12 \mathrm{mg}$ to $0.44 \mathrm{mg} / \mathrm{l})$ than that by the strain $\mathrm{KK} 4$ and were increased about twice (from $0.44 \mathrm{mg} / 1$ to
Table II. The InCREASE OF HLY SeCRetion THROUGH THE IMPROVEMENT OF STRAIN, InItial Glucose, and Mineral SALTS COMPONENTS

\begin{tabular}{ccccc}
\hline \multirow{2}{*}{$\begin{array}{c}\text { Strain } \\
\text { (Plasmid) }\end{array}$} & $\begin{array}{c}\text { Initial glucose } \\
\text { concentration } \\
(\%)\end{array}$ & $\begin{array}{c}\text { Mineral } \\
\text { salts }\end{array}$ & \multicolumn{2}{c}{ Secreted HLY } \\
\cline { 4 - 5 } & $(\mathrm{mg} / \mathrm{l})$ & (Ratio) \\
\hline $\begin{array}{c}\text { KK4 (pESH) } \\
\text { A2-1-1A } \\
\quad(\mathrm{pESH})\end{array}$ & 2 & - & 0.12 & 1.0 \\
$\begin{array}{c}\text { A2-1-1A } \\
(\mathrm{pESH}-2)\end{array}$ & 2 & - & 0.44 & 3.6 \\
$\begin{array}{c}\text { A2-1-1A } \\
(\mathrm{pESH}-2)\end{array}$ & 6 & - & 0.80 & 6.6 \\
$\begin{array}{c}\text { A2-1-1A } \\
(\mathrm{pESH}-2)\end{array}$ & 6 & - & 2.06 & 17.2 \\
$\begin{array}{c}\text { A2-l-1A } \\
(\mathrm{pESH}-2)\end{array}$ & 8 & + & 3.94 & 32.8 \\
$\begin{array}{c}\text { A2-1-1A } \\
(\mathrm{pESH}-2)\end{array}$ & 10 & + & 5.06 & 42.2 \\
\hline
\end{tabular}

a Yeast cells were grown for $120 \mathrm{hr}$ in $150 \mathrm{ml}$ of SD minimal medium supplemented with $(+)$ or without $(-)$ the effective mineral salts as shown in Fig. 3 legend.

$0.80 \mathrm{mg} / \mathrm{l})$ by duplicating the HLY transcriptional unit, and a 7 -fold further increase (from $0.80 \mathrm{mg} / 1$ to $5.54 \mathrm{mg} / \mathrm{l}$ ) was achieved by the combination of the increase in the initial glucose from $2 \%$ to $10 \%$ with the enrichment of the effective mineral salts described in this paper. Finally, we succeeded in obtaining about $5.5 \mathrm{mg}$ of HLY per liter of culture medium (46.7 fold higher than the original level of $0.12 \mathrm{mg} / \mathrm{l})$.

\section{Discussion}

Energy requirements in the eukaryotic secretory pathway are well known in many organisms. Jamieson and Palade described the energy requirement for the transport of human amylase between the ER and Golgi apparatus in the pancreatic acinar cell, ${ }^{24)}$ and Schramm showed the same requirement for the exocytosis of the secretory granule contents in the parotid gland. ${ }^{25}$ In the yeast secretory process, Novick et al. showed that energy was required for at least three steps during the transit of the secretory proteins from the ER to the cell 
surface. ${ }^{26)}$ It was also reported that the rate of glucose uptake directly controlled the adenosine phosphate pool level in yeast. $\left.{ }^{27}\right) \mathrm{We}$ assume that the increase of the initial glucose may affect not only the ENOI promoter directing the $H L Y$ gene expression but also the resulting HLY secretion, because the addition of glucose into the medium will enhance intracellular energy supply, which is necessary for the intracellular protein transport and secretion. In the yeast cells grown in the synthetic basal medium containing $8 \%$ initial glucose, the HLY secretion continued to increase linearly in proportion to the increase in the intracellular HLY, even after $24 \mathrm{hr}$ at which time the cell growth stopped and until $60 \mathrm{hr}$ at which time the glucose in the medium was exhausted by the cells (Fig. 1, Fig. 2A and B). Therefore, it is likely that the HLY secretion may be continued, even after the cells growth has stopped, by more energy, such as ATP or GTP, which will be generated by the increase of the initial glucose concentration.

There are few reports on the analysis of culture medium components for the improvement of the transcriptional efficiency and/or of the translational machinery in yeast. Tuite $e t$ al. reported that the translational efficiency was increased by using potassium acetate instead of potassium chloride as the source of $\mathrm{K}^{+}$in a cell-free protein-synthesizing system from the yeast Saccharomyces cerevisiae, because $\mathrm{Cl}^{-}$inhibited in vitro translation. ${ }^{28)} \mathrm{We}$ observed that the amounts of any cellular protein bands on Coomassie-blue-stained SDS-polyacrylamide gels were larger in the cells grown in the SD minimal medium enriched with the effective mineral salts than in the cells grown in the same medium without the enrichment of the same salts (data not shown). Therefore, it is possible that the effective mineral salts may further enhance the activity of translational machinery and a further increase in HLY production may be achieved by using potassium acetate instead of potassium chloride.

There are many reports on the secretion of foreign proteins in the yeast $S$. cerevisiae.
Ernst et al. have succeeded in obtaining $28 \mathrm{mg}$ of somatomedin-C per liter of culture medium by using multicopy vectors carrying a partially deleted $L E U 2$ gene for selection ${ }^{29)}$ and in the secretion of about $10 \mathrm{mg}$ of human granulocyte-macrophage colony-stimulatingfactor, which is an $N$-glycosylated protein, per liter. ${ }^{30)}$ In addition, human lysozyme like that in this paper was also secreted at about $19.3 \mathrm{mg}$ per liter using a mutant enzyme lacking one of the four disulfide bonds (Alasubstitutions at both cysteines 77 and 95 in lysozyme). ${ }^{31)}$ Our results, the secretion of about $5.5 \mathrm{mg}$ of HLY per liter is not as high as the above results. However, it is difficult to compare the level of the secreted proteins between the above results and our results, because the secretion level of foreign proteins in yeast is thought to be changed by differences of strains, expression vectors, promoters, and terminators, and of the proteins secreted. As an attempt at host cell improvement for foreign protein production and secretion, Kaisho et al. reported that respiratory-deficient mutants (rho- cells) of $S$. cerevisiae produced about 10 times as much human lysozyme as did wild-type strains ( rho $^{+}$cells) when the $G A L 10$ promoter was used in an expression plasmid with the $H L Y$ gene. ${ }^{32)}$ We also isolated a supersecreting mutant, which showed about a 10 -fold increase in the secretion of HLY under the ENOI promoter (manuscript in preparation). Accordingly, the combination of the culture conditions described in this paper with the yeast mutant described above will further improve the level of HLY production and secretion, which is in progress and probably will be useful for other foreign protein secretion.

Fieschko et al. have described the conditions for high-cell-density fermentations of $S$. cerevisiae producing recombinant-DNA-derived proteins. ${ }^{33)}$ Under the induced conditions, where the high cell densities with higher plasmid stability were maintained by switching from a glucose-limiting feed to a galactoselimiting feed, they obtained human interferon (IFN- $\gamma$ ) production as $3 \sim 5 \%$ of total cellular 
proteins ( $2 \mathrm{~g}$ IFN/1 fermentation culture) by using a hybrid yeast GPD (glyceroaldehyde 3phosphate dehydrogenase gene) promoter that was subject to carbon source regulation due to the presence of regulatory DNA sequences from the yeast $G A L I, 10$ intergenic region. Suomalainen reported that the glucose concentrations above $5 \%$ caused repression of the oxidative pathway, resulting in ethanol accumulation even under aerobic conditions. ${ }^{34}$ ) Taken together, since the commercial baker's yeast ( $S$. cerevisiae) grown on a limited carbon source like molasses is known to contain a large amount of enolase, ${ }^{35}$ ) the existence of a limited amount of a glycolytic carbon source, like glucose, in the medium at any culture periods, may be important for the expression of ENOI gene and resultant protein production and secretion. Thus, a further study to increase the HLY secretion under the ENOI promoter may be work in a fed-batch culture system with a limited but constant supply of glucose into the medium.

Acknowledgments. We are very grateful to Dr. T. Fukasawa and Mr. T. Ohya for providing the yeast strains KK4 and A2-1-1A, respectively.

\section{References}

1) E. F. Osserman, R. E. Canfield and S. Beychok, "Lysozyme," Academic Press, New York, 1974.

2) L. I. Gordon, S. D. Douglas, N. E. Kay, O. Yamada, E. F. Osserman and H. S. Jacob, J. Clin. Invest., 64, 226 (1979).

3) M. Muraki, Y. Jigami, H. Tanaka, N. Harada, F. Kishimoto, H. Agui, S. Ogino and S. Nakasato, Agric. Biol. Chem., 50, 713 (1986).

4) Y. Jigami, M. Muraki, N. Harada and H. Tanaka, Gene, 43, 273 (1986).

5) H. Uemura, Y. Jigami, H. Tanaka, N. Toshimitu, $M$. Paterson and S. Nakasato, J. Biochem., 98, 859 (1985).

6) K. Ichikawa, T. Nakahara, H. Uemura and Y. Jigami, Agric. Biol. Chem., 53, 1445 (1989).

7) R. A. Smith, M. J. Duncan and D. T. Moir, Science, 229, 1219 (1985).

8) A. Sakai, Y. Shimizu and F. Hishinuma, Genetics, 119, 499 (1988).

9) P. Caunt, A. Impoopsup and P. F. Greenfield, $J$. Biotech., 8, 173 (1988).
10) K. S. Zaret and F. Sherman, J. Mol. Biol., 176, 107 (1984).

11) T. C. Santiago, A. J. E. Bettany, I. J. Purvis and A. J. P. Brown, Nucleic Acid Res., 15, 2417 (1987).

12) T. Hayakawa, A. Toibana, R. Marumoto, K. Nakahama, M. Kikuchi, K. Fujimoto and $M$. Ikehara, Gene, 56, 53 (1987).

13) Y. Yamamoto, Y. Taniyama, M. Kikuchi and $M$. Ikehara, Biochem. Biophys. Res. Commun., 149, 431 (1987).

14) R. K. Appleyard, Genetics, 39, 440 (1954).

15) Y. Jigami, N. Toshimitu, H. Fujisawa, H. Uemura, H. Tanaka and S. Nakasato, J. Biochem., 99, 1111 (1986).

16) Y. Nogi, H. Shimada, Y. Matsuzaki, H. Hashimoto and T. Fukasawa, Mol. Gen. Genet., 195, 29 (1984).

17) S. N. Cohen, A. C. Y. Chang and L. Hsu, Proc. Natl. Acad. Sci. U.S.A., 69, 2110 (1972).

18) H. Ito, Y. Fukuda, K. Muraki and A. Kimura, J. Bacteriol., 153, 163 (1983).

19) F. Sherman, G. R. Fink and J. B. Hicks, "Methods in Yeast Genetics," A Laboratory Manual, Cold Spring Harbor Laboratory, Cold Spring Harbor, N. Y., 1982, pp. $61 \sim 62$.

20) T. Maniatis, E. F. Fritsch and J. Sambrook, "Molecular Cloning," A Laboratory Manual, Cold Spring Harbor Laboratory, Cold Spring Harbor, $\mathrm{N}$. Y., 1982.

21) P. Morsky, Anal. Biochem., 128, 77 (1983).

22) C. A. Kaiser and D. Botstein, Mol. Cell. Biol., 6, 2382 (1986).

23) U. K. Laemmli, Nature, 227, 680 (1970).

24) J. Jamieson and G. Palade, J. Cell Biol, 39, 589 (1968).

25) M. Schramm, Ann. Rev. Biochem., 36, 307 (1981).

26) P. Novick, S. Ferro and R. Schekman, Cell, 25, 461 (1981).

27) M. D. Akbar, P. A. D. Rickard and F. J. Moss, Biotechnol. Bioeng., 16, 455 (1974).

28) M. F. Tuite, J. Plesset, K. Moldaue and C. S. McLaughlin, J. Biol. Chem., 255, 8761 (1980).

29) J. F. Ernst, $D N A, 5,483$ (1986).

30) J. F. Ernst, J. J. Mermod, J. F. DeLamarter, R. J. Mattaliano and P. Moonen, Biotechnology, 5, 831 (1987).

31) Y. Taniyama, Y. Yamamoto, M. Nakao, M. Kikuchi and M. Ikehara, Biochem. Biophys. Res. Commun., 152, 962 (1988)

32) Y. Kaisho, K. Yoshimura and K. Nakahama, Yeast, 5, 91 (1989).

33) J. C. Fieschko, K. M. Egan, T. Ritch, R. A. Koski, M. Jones and G. A. Bitter, Biotechnol. Bioeng., 29, 1113 (1987).

34) H. Suomalainen, J. Microbiol. Serol., 35, 83 (1969).

35) M. J. Holland and J. P. Holland, Biochemistry, 17, 4900 (1978). 